\title{
Ueber eine schon beschriebene, aber noch nicht benannte österreichische Dipterenart.
}

\author{
Von Jos. Mik in Wien.
}

Coenosia (Caricea) Stroblii n. sp.

of o Thorace cinereo, abdomine ferrugineo, basi subtranslucente, segmentis secundo, tertio et quarto certo situ brunneo. bimaculatis, stria brunnea maculis interposita; pictura in feminae abdomine vix conspicua; pedibus ferrugineis, femoribus anticis excepto apice cinereis. Fronte grisea, maculis cuneiformibus nigrescentibus binis; antennis cum halteribus ferrugineis, illarum articulo tertio infuscato, arista plumosula, palpis testaceis; alis pallide lutescenti-cinerascentibus, venutis transversis crassioribus, non obumbratis. Long. corp. circa $5 \mathrm{~mm}$, long. alar. $4 \mathrm{~mm}$.

Patria: Austria inferior, Illyria.

Diese Art wurde von Herrn Prof. P. G. Strobl im XIV. Programme des k. k. Obergymnasiums der Benedictiner in Seitenstetten (Separatabdr. Linz 1880, pag. 25) kenntlich genug beschrieben, doch nur als fraglich neue Art hingestellt und nicht benannt. Er hat ein Pärchen derselben bei Seitenstetten (Niederösterreich) gesammelt und darüber Folgendes mitgetheilt: "Die Bestimmung (dieser Art) führt in Schine r auf Coenosia alma, von der sie sich aber unterscheidet durch scheinbar ganz ungefleckt rothen Hinterleib - 3 Paare von Punkten sind allerdings rothbraun angedeutet - gelblichgrauen Kopf, rothe, nur am letzten Gliede grösstentheils schwarze Fühler, bis auf die - mit Ausnahme der Spitze grauen Vorderschenkel ganz rothe Beine und ungesäumte Queradern. Grösse $2^{1 / 3}$ Lin. Das Weibchen ganz so wie das Männchen, die Punkte noch blässer."

Nachdem Herr P. Strobl durch obige Beschreibung auf die Art zuerst aufmerksam gemacht hat, erlaube ich mir, ihm dieselbe zu widmen. Ich habe sie viel früher in der Umgebung von Görz im Kïstenlande gefangen, und zwar Anfangs Mai 1865 auf feuchtem alten Laube in Waldschluchten jenseits des Isonzo; im September 1867 fand ich dieselbe Art in einer feuchten Waldschlucht bei Dornbach nächst Wien. Herr E. Pokorny traf sie an ähnlicher Stelle im Wienerwalde bei Rekawinkel. 
Man kann Coenosia Stroblii m. mit ihrer nächsten Verwandten Coenosia alma Meig. in die Gattung Caricea Rond., Meade bringen, wenn man überhaupt dieser Gattung Geltung belassen will. Der Hauptunterschied derselben gegenüber der Gattung Coenosia s. str. liegt in der Fühlerborste, welche bei Caricea wenigstens an der Basis plumulos, bei Coenosia aber pubescent genannt wird. Meigen und Schine r nennen die Borste bei Coenosia alma nackt, während $\mathrm{Z}$ etterstedt von ihr sagt: „seta subnuda seu vix visibiliter puberula". Das Exemplar von Coenosia alma, welches sich in meiner Sammlung: befindet, hat eine genug deutlich plumulose Fühlerborste, wenn auch nicht so entschieden, wie es bei Coenosia Stroblii der Fall ist. Man sieht also hieraus, dass entweder die Auffassung der Behaarung der Fühlerborste bei C. alma von Seiten der Autoren eine verschiedene, oder dass die Behaarung bei dieser Art eine variable ist, demzufolge die Entscheidung für die eine oder die andere der genannten Gattungen unsicher erscheint.

Der Beschreibung, welche Herr P. Strobl von unserer Art 1. c. gegeben hat, möchte ich noch Folgendes hinzufügen. Das Männchen besitzt einen etwas längeren Hinterleib als jenes von $C$. alma und erscheint daher etwas schlanker. In beiden Geschlechtern ist die Stirn fast gleich breit, die Strieme derselben ist schwärzlich und vom Scheitel her fast bis zu den Fühlern von einem grauen dreieckigen Flecke tief gespalten, so dass eine aus zwei keilförmigen, mit der Spitze gegen den Scheitel gekehrten Längsflecken bestehende Doppelstrieme gebildet wird. Ausser dem einen Paare oberer, sehr grosser Stirnborsten finden sich jederseits je vier, auf schwärzlichen, runden kleinen Makeln stehende, recht lange untere Frontoorbitalborsten. Die zwei Ocellarborsten sind gleichfalls stark entwickelt.

Auf den Schulterbeulen befinden sich je 2 Macrochaeten; die äussere derselben ist stärker entwickelt. Die äusseren Reihen der Dorsocentralborsten bestehen aus je 5 Macrochaeten, wovon 3 hinter der Quernaht des Thorax stehen; statt der inneren Dorsocentralborsten finden sich in 2 Reihen geordnete, aber nicht paarweise stehende Acrostichalbörstchen, welche vor der Quernaht etwas länger sind, als hinter derselben. Zwischen den Mocrochaeten des Thoraxrückens und am Schildchen stehen sehr zerstreute, kurze Börstchen; letzteres trägt am Rande 4 sehr lange Macrochaeten. Am Thoraxrücken des Weibchens 
zeigen sich zuweilen zwei bräunliche Längslinien, wo die äusseren Dorsocentralborsten stehen. Alle Borsten sind schwarz.

Der Hinterleib des Männchens zeigt die bräunlichen Flecken am deutlichsten, wenn man ihn schief von rückwärts besieht; die Seiten erscheinen dann mit einem weisslichgrauen Dufte belegt. Auch die ununterbrochene Rückenstrieme, von ähnlicher Farbe wie die Flecke, erscheint nur in gewisser Richtung; sie erstreckt sich bis gegen den Hinterrand des 4. Ringes. Der Körper des Hypopygs, d. i. der 6. Hinterleibsring, hat die Farbe des vorhergehenden Ringes und hinten (an der Spitze des Hinterleibes) ein länglichrundes tiefes Grübchen, in welchem sich ein nabelförmiges Leistchen erhebt; die Anhänge des Hypopygs werden von den nach abwärts etwas ausgezogenen Seitentheilen des 4. Segmentes eingeschlossen; der Rand dieser Seitentheile ist glänzend rostgelb, kahl und einmal eingebuchtet. Die Beborstung des Hinterleibes, namentlich jenes des Weibchens, ist wenig auffallend, da die längeren Borsten nur wenig über die kürzeren hervorragen. Von der Zeichnung sieht man am weiblichen Hinterleib nur Spuren, namentlich wenn er getrocknet ist, da in diesem Zustande, wie es häufig bei hellgefärbten Anthomyinen geschieht, unregelmässige dunkle Flecken am Hinterleibe auftreten und dann nicht selten solche Zeichnungen leicht verdecken, welche sich nicht deutlich von der Grundfarbe abheben.

Die Hüften sind zum grössten Theile hellgrau bestäubt, nur gegen die Spitze zu zeigt sich die rostgelbe Grundfarbe; die Schenkelringe sind rostgelb oder roströthlich wie die übrigen Theile der Beine, wovon auch die Tarsen keine Ausnahme machen; nur die Vorderschenkel sind, bis auf einen kleinen Theil an der Spitze, grau, an der Hinterseite jedoch in grösserer Ausdehnung als an der Vorderseite. An den Hinterschienen fällt auf deren Oberseite vor der Spitze eine lange gerade, schwarze Borste auf; an der Hinterseite dieser Schienen, mehr gegen die Oberseite zu, befinden sich in gleichen Abständen vertheilt 3 längere Borsten. Pulvillen und Klauen des Weibchens sind viel kürzer als jene des Männchens.

Die Schüppchen sind weiss, in ihrer Bildung zeigen sie den Gattungscharakter, wie er von $\mathrm{R}$ on d an i angegeben wird; dasselbe gilt von dem Flügelgeäder. Die beiden Queradern sind etwas verdickt, aber nicht umschattet, wie es bei $C$. alma der Fall ist. 


\section{$2 \mathrm{BHL}$ Biodiversity Heritage Library}

Mik, Josef. 1887. "Ueber eine schon beschriebene, aber noch nicht benannte österreichische Dipterenart." Wiener entomologische Zeitung 6, 261-263. https://doi.org/10.5962/bhl.part.17764.

View This Item Online: $\underline{\text { https://www.biodiversitylibrary.org/item/44060 }}$

DOI: https://doi.org/10.5962/bhl.part.17764

Permalink: https://www.biodiversitylibrary.org/partpdf/17764

\section{Holding Institution}

Smithsonian Libraries

\section{Sponsored by}

Smithsonian

\section{Copyright \& Reuse}

Copyright Status: NOT_IN_COPYRIGHT

This document was created from content at the Biodiversity Heritage Library, the world's largest open access digital library for biodiversity literature and archives. Visit BHL at https://www.biodiversitylibrary.org. 